\title{
Location-based Mobile Games in mHealth: A Preliminary Study of Pokémon Go in Promoting Health Exercising
}

\author{
Fang-Yi Flora Wei \\ Department of Mass Media Arts \\ Clark Atlanta University \\ Atlanta, GA 30314, USA \\ fwei@cau.edu \\ Y. Ken Wang \\ Division of Management and Education \\ University of Pittsburgh at Bradford \\ Bradford, PA 16701, USA \\ ykw@pitt.edu
}

\begin{abstract}
Location-based mobile games such as Pokémon Go might improve players' physical activities (e.g., walking) and social interactions. With a limited research on mobile exergaming activities, this study examined relationships among Pokémon Go players' gaming activities, willingness to communicate, and the likelihood of engaging in exercises. Our study showed that the longer participants had been playing the game, the higher the likelihood that they would engage in exercises. Our findings revealed a positive relationship between exercise during gameplay and willingness to communicate with other players. Our study provides implications to the use of location-based mobile games to promote health campaigns and improve the general health of the population.
\end{abstract}

\section{Introduction}

Recent health campaigns have relied heavily on media to persuade people to engage in healthy behaviors [1]. In the meantime, Kwan, Mechael, and Kaonga reported that nearly 5.3 billion people around the world can be reached by mobile phones [2]. Thanks to the popularity of smartphones, text messaging and mobile gaming activities might be used to change people's behav- iors in health programs [2]. The use of mobile phones to promote healthy behaviors is so-called "mHealth."

One potential intriguing use of smartphones in mHealth is exergaming, which refers to the use of electronic games to facilitate physical activities [3]. In particular, a free mobile application game, Pokémon Go, released on July 6, 2016 by Nintendo, had 25 million daily active players after only one month of the official release [4]. This mobile game involves players becoming a Pokémon trainer by catching more than 100 Pokémon monsters via their smartphones [5]. To catch Pokémon monsters, players have to travel to various geographical locations at a speed lower than 20 miles per hour, which suggests that they have to walk, jog, or ride a bike when they play the game. Reserach [6] found that Pokémon Go players took on average 5,211 steps per day after their first week of playing, compared to 4,256 steps prior to the installation.

In addition to the potential benefits in active physical activities [7], this exergaming activity may also promote social interaction [8]. Due to the interactive function of displaying their physical locations on the mobile map, Pokémon players have an opportunity to communicate with other game players in "PokeStops" (specific places where players can enhance their gaming supplies [5]), which provide opportunities to engage in social interaction with unknown individuals and cultivate communicative skills for those who might not interact socially. 
Thus, this study examines relationships among Pokemon Go players' gaming activities, willingness to communicate, and likelihood of engaging in physical exercises.

\section{Rationale and Hypotheses}

\section{1. mHealth Gaming Campaigns and Activities}

Common mHealth campaigns activities are traditionally categorized into two categories: text-oriented campaigns activities and gaming-oriented campaigns activities. Examples of text-oriented intervention and their particular health foci include "Stop Smoking with Mobile Phones" (STOMP) in New Zealand (or text2stop in UK [9]), the SMS (Short Message Service) campaign to prevent HIV and/or AIDS in Uganda [10], the Mobile Mums campaign in Australia to increase physical activities [11], and the STAR (Study of Technology to Accelerate Research) campaign to promote dieting habits and prevent obesity prevention [12]. Those interventions emphasize on reinforcing a healthy behavior by exposing people repeatedly to informative or persuasive information via text messaging.

Other health campaigns, however, such as Freedom HIV/AIDS in India [13], have employed mobile phone games as a form of entertainment education, "the design and delivery of education using entertainment formats" [14]. The edutainment approach also has been adopted by health campaign designers to develop computer and online games; for instance, the role-playing involved in the RightWay Café computer game promotes participants' healthy eating behavior [15], and an online drinking game has been shown to reduce alcohol consumption [16]. Based on the role-play (virtual involvement), players learned to make the adequate decisions in similar real-time situations.

\subsection{Exergaming and physical activities}

A serious blame in applying electronic gaming activity on health program is that most players get used to play video/computer games in a sedentary position [17] . To change the sedentary gaming culture along with moderate outdoor activities, exergaming (a combination of exercise and gaming) is prone to motivate players' engagement in physical activities during their gaming activities [7] [17]. Exergaming has become successfully applied across different ages of players; for example, in investigating the potential effects of exergaming on physical activities among 5th graders, "the results showed that exergaming produced substantially more minutes of physical activity for each participant than did PE [physical education] [3]. By using a sample of 1,241 grade 10 and 11 students, O'Loughlin, Dugas, Sabiston, and O'Loughlin [18] concluded that "exergaming is a popular activity that provides opportunities for adolescents to engage in healthy levels of PA [physical activities] as well as reduce sedentary time" (p. 811). Furthermore, exergaming is also found to improve the motor functions of the elderly in a short period of time, as well as to motivate them to present a high exercise continuation rate [19]. Yet, the contradicted findings (e.g., Baranowski et al. [20]; LeBlanc et al. [21]) also showed that playing active video games has no effect to promote participants' engagement in the habitual physical activities. Therefore, we are skeptic about whether a mobile exergaming promotes players' physical activities during mobile game playing, as well as how well this "on the move" playing habit facilitates future exercise continuation rates.

\subsection{Willingness to Communication}

In addition to the aforementioned contradicted finding in participants' engagement in physical activities, one of neglected areas is whether exergaming promotes players' willingness to communication. Because changing social support can dynamically increase physical activity [22], doing an exercise needs peers' companionship (exercise buddies [12]). Such a companionship (shared interest) seems to motivate exercise buddies to facilitate an informal social interaction or conversation easily. However, the perceiving problem is that people who are addicted to traditional electronic gaming activity tend to have little social interaction [23]; indeed, they may avoid engaging in a face-to-face interaction with other people. Unlike a traditional electronic game, whether this mobile exergaming activity has the potential to promote players' willingness to communicate with other players (e.g., unfamiliar users or strangers) is still unclear. Thus, we posted the following three hypotheses:

- H1: There is a positive relationship between history of playing Pokémon Go and exercises (e.g., walking) during Pokémon Go play.

- H2: There is a positive relationship between participants' engagement in exercises during Pokémon Go play and (a) short-term and (b) long-term likelihood of consistently engaging in exercises. 
- H3: There is a positive relationship between participants' engagement in exercises during Pokemon Go play and their willingness to communication with (a) strangers, (b) acquaintances, and (c) friends.

\section{Methods}

\subsection{Participants}

Four hundred and three participants (Mage $=26.42$, $\mathrm{SD}=10.73$, Range $=66)$ who owned a smartphone and played Pokémon Go were recruited voluntarily to complete a survey questionnaire. The data were collected 2 months after the release of the game in the U.S. The sample consisted of $65.8 \%$ males and $34.2 \%$ females, with 51.6\% being Caucasian, $18.9 \%$ Asian, $14.4 \%$ Hispanic, African American $8.7 \%$, other races 5\%, and Latino $1.5 \%$.

\subsection{Procedures}

One of the authors and her assistant identified popular PokeStops on a mobile map for the purpose of data collection in a major city of the southeastern United States. They waited in those locations for two weeks to identify potential participants who held a smartphone with the possibility of being Pokémon Go players. They also approached Pokémon Go players on a daily basis in public parks and shopping centers. For those Pokémon players who were minors (younger than 18 years old), the researchers gained parental or guardian permission prior to the administration of the survey. A total of 420 people participated in the survey. Eventually 403 completed anonymous questionnaires were used in data analysis.

\subsection{Measured Variables}

History of playing Pokémon Go. Participants' history of playing Pokémon Go was measured by the question, "After the game was released, how long have you been playing Pokémon Go?" using a number to represent the number of months, weeks, or days. Researchers recoded and converted participants' responses into days $(\mathrm{M}=50.44, \mathrm{SD}=16.36)$. To verify whether highly skewed numbers occurred due to participants' false recall, participants reported their gaming level. A gaming level is defined by experience points evaluated by this gaming software automatically.

Exercising during Pokémon Go play. To measure whether participants exercised while playing Pokémon
Go, four questions were asked, with each question proceeded by "In a typical weekday (and, separately, "typical weekend"), how much time do you spend per day": "on 'walking' while playing Pokémon Go?" and "on other outdoor exercising (e.g., jogging or bicycling) while playing Pokémon Go?" Participants reported their responses in hours or minutes, which were recoded and converted into minutes.

The likelihood of exercising. Short-term likelihood of engaging in exercises. Based on McAuley (1993)'s self-efficacy and maintenance of exercise scale in the field of behavioral medicine, the first four statements such as "I am able to continue to exercise three times per week at moderate intensity, for 40+ minute without quitting for the next week," and "I am able to continue to exercise three times per week at moderate intensity, for $40+$ minutes without quitting for the next two weeks" were applied in a sequent order. This pre-established scale required participants to circle one of the percentage from $0 \%$ to $100 \%(0 \%=$ Not at all Confident, $50 \%=$ Moderately Confident, and 100\% = Highly Confident).

Long-term likelihood of engaging exercises. By using the same self-efficacy and maintenance of exercise scale in McAuley (1993), the last four statements such as "I am able to continue to exercise three times per week at moderate intensity, for $40+$ minutes without quitting for the next five weeks" and "I am able to continue to exercise three times per week at moderate intensity, for $40+$ minutes without quitting for the next eight weeks" were employed in a sequent order.

Willingness to communicate. Based on McCroskey's willingness to communicate (WTC) scale [24] , 12 items (four each) were used to measure WTC with strangers, acquaintances, and friends during their Pokémon Go play. For each item, participants indicated a number between 0 and $100(0=$ Never to $100=\mathrm{Al}-$ ways).

Demographic information. Participants identified their birth year to indicate their age and circled their gender and ethnicity from a list.

\subsection{Data Analysis}

The proposed hypotheses in the research model (see Figure 1) were tested. The data analysis was performed using a structural equation model (SEM) with path analysis, to demonstrate the fitness of the hypotheses with the criteria of CFI greater than .90, SRMR less than .10, and RMSEA less than .10 [25]. 


\subsection{Preliminary Result}

The descriptive statistics are reported in Table 1 . The path analysis was conducted in in M-plus 5.2 [26]. Age and ethnicity were entered as control variables. The model yielded CFI $=.912$, SRMR $=.038$, and RMSEA $=.096$, all indicated satisfactory overall fitness of the model and the collected data set.

As to the path weights, there was a significant path between history of playing and engaging in exercise ( $\mathrm{p}=$ .031). This path provided support to $\mathrm{H} 1$, suggesting that those who played Pokémon Go game longer generally were more actively engaged in exercise.

The several paths between engaging in exercise and willingness to communication demonstrated different results depending on the situations. The participants who were actively engaged in exercise were more willing to communicate with strangers $(\mathrm{p}<.001)$ and acquaintance $(\mathrm{p}=.010)$, thus $\mathrm{H} 3 \mathrm{a}$ and $\mathrm{H} 3 \mathrm{~b}$ were supported. However, the path between engaging in exercise and willingness of communication with friends was not significant ( $\mathrm{p}=.093$ ), thus failed to support H3c. Such rejection may be partially attributed to the diverse factor loadings in the measurement of WTC with friends.

The model yielded two significant paths between engaging in exercise and likelihood of consistent engaging in exercise, both short term $(\mathrm{p}=.036)$ and long term $(\mathrm{p}=$ $.010)$, suggesting that the participants who were actively engaged in exercise were more likely to consistently engaging in future exercise.

\section{Discussion}

This preliminary study examined whether Pokémon Go has the potential to motivate individuals to exercise (e.g., walking), as well as facilitate their willingness to communicate with other players. The results showed that history of playing Pokémon Go was related positively to players' exercise during Pokémon Go play, meaning that the longer participants had been playing Pokémon Go, the more time they walked or engaged in other moderate outdoor exercises. Given Pokémon Go's rule of traveling with a smartphone under 20 miles per hour, most players may consider walking (or moving around physically) to be a natural part of this mobile gaming activity. Because the goal of the game is to collect Pokémon monsters across geographic locations, players are likely to sustain their attention on the mobile gaming activities and pay little attention to the distance that they have walked in which they engaged. This mobile game, per se, may be a persuasive message that mo- tivates walking. This mHealth strategy reflects the idea of learning by doing (playing).

This study also tested the relationship between Pokémon Go players' exercises during their play and their likelihood of engaging in more than 40 minutes of exercises at least three times per week at a moderate intensity without quitting. The results revealed that players' exercise (e.g., walking) during their Pokémon Go play was related positively to their self-reported confidence in continuing that exercise. To avoid the potential biases, we interpreted this finding with caution that players engaged in certain physical activities due to their enthusiasm toward the game. However, it is unpredictable whether the impact of the exergaming on their participation may fade away if they are no longer interested in playing the game. Besides promoting the likelihood of walking, Pokémon Go has been noted to motivate players' social interaction [8].

The results of this study showed that there was a positive relationship between players' exercise during their play and their willingness to communicate with other players. Price et al.'s study suggested that "exercise buddies" are expected to be friends rather than a group of unknown individuals [12]; however, to collect Pokémon monsters effectively, game players have to move physically at any time across many locations. Part of the excitement of the game is that players hardly know when and where they will catch what type of monsters; consequently, often, they run together with several strangers to catch a Pokémon monster. Interactions with those unfamiliar players may begin with a simple question, such as "Where did you catch Dragonite [the rare type of Pokémon]?" Consequently, players might be willing to communicate with other players (e.g., strangers or acquaintances) while playing the game due to the rewards obtained from the game. In line with the study by Reinders and Wattana [27], Pokémon Go results in an increased willingness to communicate with other players, potentially extending players' social ties to unknown individuals. Reinders and Wattana explained that people's willingness in communication is influenced by social contexts (situational conditions), so a low anxiety gaming environment may led players to interact with others "without paying attention" to their own uneasiness in communication. Therefore, the exergaming format in Pokémon Go might be used to help those players with low social confidence to engage in conversation with others. 


\section{Limitations}

The results from this study need to be interpreted in light of at least three potential limitations. First, participants' sedentary behaviors and weight were not collected in this survey, which should be used as a covariate to enrich the future data analyses. Second, the data were collected during early September, when the weather is between 70 and 80 degrees. Whether Pokémon Go players' engagement in physical activities is influenced by other weather conditions is uncertain. Finally, this study did not measure the amount of exercise in which players originally engaged, especially when not playing the game. A follow-up study may need to determine whether they would engage in the same type of exercising when they are away from the exergaming.

\section{Conclusion}

This preliminary study tested whether Pokémon Go has the potential to promote exercise and willingness to communicate for the purpose of determining whether this game can be used as a potential mHealth intervention. Although mobile-mediated technology now is used in health campaigns, the majority of them have focused on text messaging. The present study, however, found that a mobile phone game, Pokémon Go, can facilitate participants' walking and interactions with other players. The most interesting finding is that this mobile game motivated users to engage in exercising and communication, but those players might not consciously feel that they are doing it, which might open the possibility for future mHealth program to promote healthy behaviors via a similar exergaming activity.

\section{References}

[1] M. Haug, "Do campaigns really change behavior?" Nordicom Review, vol. 25, no. 1-2, pp. 277-290, 2004. [Online]. Available: https : / / content . sciendo.com/view/journals/nor/25/12/article-p277.xml.

[2] A. Kwan, P. Mechael, and N. Kaonga, "State of behavior change initiatives and how mobile phones are transforming it," MHealth in practice: Mobile technolocy for health promotion in the developing world. London: Bloomsbury Academic, pp. 15-31, 2013.

[3] V. A. Fogel, R. G. Miltenberger, R. Graves, and S. Koehler, "The effects of exergaming on physical activity among inactive children in a physical education classroom," Journal of applied behavior analysis, vol. 43, no. 4, pp. 591-600, 2010.
[4] N. Mediati. (Jul. 2016). Surveymonkey: Pokémon go popularity may have already peaked, [Online]. Available: https : / / www . pcworld. com/article / 3098895 / software-games / surveymonkeypokmon - go - popularity - may - have already-peaked.html (visited on 06/07/2018).

[5] C. Bennett and D. Scimeca. (Feb. 2017). Pokémon go: A beginner's guide for getting started, [Online]. Available: https : / / www. dailydot.com/parsec / pokemon-go-guide/ (visited on 06/07/2018).

[6] K. B. Howe, C. Suharlim, P. Ueda, D. Howe, I. Kawachi, and E. B. Rimm, "Gotta catch'em all! pokémon go and physical activity among young adults: Difference in differences study," $B m j$, vol. 355 , p. i6270, 2016.

[7] T. Baranowski, "Exergaming: Hope for future physical activity? or blight on mankind," J Sport Health Sci, vol. 6, no. 1, pp. 44-46, 2017.

[8] R. Cho. (2016). How "pokemon go" is helping kids with autism and asperger's, [Online]. Available: http: / / www . cnn . com / 2016/08/05/health / pokemon-go-autism-aspergers.

[9] C. Free, "Developing and adapting a text messaging intervention for smoking cessation from new zealand for the united kingdom," MHealth in practice mobile technology for health promotion in the developing world. London: Bloomsbury Accademic, 2012.

[10] H. van Beijma and B. Hoefman, "Text to change: Pioneers in using mobile phones as persuasive technology on health in africa," MHealth in Practice: Mobile technology for health promotion in the developing world. London: Bloomsbury Academic, 2012.

[11] B. S. Fjeldsoe, Y. D. Miller, J. L. O’Brien, and A. L. Marshall, "Iterative development of mobilemums: A physical activity intervention for women with young children," International Journal of Behavioral Nutrition and Physical Activity, vol. 9, no. 1, p. 151, 2012.

[12] A. E. Price, S. J. Corwin, D. B. Friedman, S. B. Laditka, N. Colabianchi, and K. M. Montgomery, "Older adults' perceptions of physical activity and cognitive health: Implications for health communication," Health Education \& Behavior, vol. 38, no. 1, pp. 15-24, 2011.

[13] S. Quraishi and H. Quraishi, "Freedom hiv/aids: Mobile phone games for health communication and behaviour change," MHealth in Practice: Mobile technology for health promotion in the developing world, pp. 146-161, 2012. 
[14] G. X. Ayala, L. Ibarra, L. Horton, E. M. Arredondo, D. J. Slymen, M. Engelberg, C. L. Rock, E. Hernandez, H. Parada, and J. P. Elder, "Evidence supporting a promotora-delivered entertainment education intervention for improving mothers' dietary intake: The entre familia: Reflejos de salud study," Journal of health communication, vol. 20, no. 2, pp. 165-176, 2015.

[15] W. Peng, "Design and evaluation of a computer game to promote a healthy diet for young adults," Health communication, vol. 24, no. 2, pp. 115-127, 2009.

[16] K. Croom, L. Staiano-Coico, M. L. Lesser, D. K. Lewis, V. F. Reyna, T. C. Marchell, J. Frank, and S. Ives, "The glass is half full: Evidence for efficacy of alcohol-wise at one university but not the other," Journal of health communication, vol. 20, no. 6, pp. 627-638, 2015.

[17] L. Görgü, A. Campbell, M. Dragone, and G. M. O'Hare, "Exergaming: A future of mixing entertainment and exercise assisted by mixed reality agents," Computers in Entertainment (CIE), vol. 8, no. 4, p. 27, 2010.

[18] E. K. O’Loughlin, E. N. Dugas, C. M. Sabiston, and J. L. O'Loughlin, "Prevalence and correlates of exergaming in youth," Pediatrics, vol. 130, no. 5, pp. 806814, 2012.

[19] Y. Nagano, K. Ishida, T. Tani, M. Kawasaki, and M. Ikeuchi, "Short and long-term effects of exergaming for the elderly," SpringerPlus, vol. 5, no. 1, p. 793, 2016.

[20] T. Baranowski, D. Abdelsamad, J. Baranowski, T. M. O'Connor, D. Thompson, A. Barnett, E. Cerin, and T.-A. Chen, "Impact of an active video game on healthy children's physical activity," Pediatrics, peds-2011, 2012.

[21] A. G. LeBlanc, J.-P. Chaput, A. McFarlane, R. C. Colley, D. Thivel, S. J. Biddle, R. Maddison, S. T. Leatherdale, and M. S. Tremblay, "Active video games and health indicators in children and youth: A systematic review," PLoS One, vol. 8, no. 6, e65351, 2013.

[22] D. N. Cavallo, J. D. Brown, D. F. Tate, R. F. DeVellis, C. Zimmer, and A. S. Ammerman, "The role of companionship, esteem, and informational support in explaining physical activity among young women in an online social network intervention," Journal of behavioral medicine, vol. 37, no. 5, pp. 955-966, 2014.

[23] M. Griffiths, "Does internet and computer "addiction" exist? some case study evidence," CyberPsychology and Behavior, vol. 3, no. 2, pp. 211-218, 2000.

[24] J. C. McCroskey, "Reliability and validity of the willingness to communicate scale," Communication Quarterly, vol. 40, no. 1, pp. 16-25, 1992.

[25] R. B. Kline and D. A. Santor, "Principles \& practice of structural equation modelling," Canadian Psychology, vol. 40, no. 4, p. 381, 1999.
[26] L. K. Muthén et al., "Mplus: Statistical analysis with latent variables (version 4.21)[computer software," 2007.

[27] H. Reinders and S. Wattana, "Can i say something? the effects of digital game play on willingness to communicate.," 2014. 
Table 1. Descriptive statistics

\begin{tabular}{|c|c|c|c|c|c|c|c|}
\hline Item & $\begin{array}{l}\text { Range } \\
(0-)\end{array}$ & Mean & S.D. & $\begin{array}{c}\text { Skew- } \\
\text { ness }\end{array}$ & $\begin{array}{l}\text { Kurto- } \\
\text { sis }\end{array}$ & $\begin{array}{c}\text { Factor } \\
\text { Load- } \\
\text { ing }\end{array}$ & $\begin{array}{l}\text { Cron- } \\
\text { bach's } \\
\text { Alpha }\end{array}$ \\
\hline History of Playing & 69 & 50.44 & 16.36 & -1.477 & 1.172 & n.a. & n.a. \\
\hline Engaging in Exercise, walking weekdays & 720 & 128.11 & 137.54 & 2.064 & 4.966 & 0.799 & \multirow[t]{4}{*}{0.834} \\
\hline Engaging in Exercise, walking weekends & 1200 & 224.03 & 196.71 & 1.489 & 2.905 & 0.789 & \\
\hline $\begin{array}{l}\text { Engaging in Exercise, outdoor exercising } \\
\text { weekdays }\end{array}$ & 720 & 82.57 & 122.57 & 2.461 & 7.343 & 0.843 & \\
\hline $\begin{array}{l}\text { Engaging in Exercise, outdoor exercising } \\
\text { weekends }\end{array}$ & 1200 & 128.43 & 173.10 & 2.191 & 6.121 & 0.845 & \\
\hline $\begin{array}{l}\text { Willingness of Comm., to a group of } \\
\text { strangers }\end{array}$ & 100 & 54.89 & 35.47 & -0.200 & -1.352 & 0.806 & \multirow[t]{4}{*}{0.892} \\
\hline $\begin{array}{l}\text { Willingness of Comm., in a small group of } \\
\text { strangers }\end{array}$ & 100 & 62.84 & 32.99 & -0.482 & -1.043 & 0.850 & \\
\hline Willingness of Comm., with a stranger & 100 & 60.15 & 34.67 & -0.430 & -1.182 & 0.806 & \\
\hline $\begin{array}{l}\text { Willingness of Comm., in a large meeting } \\
\text { of strangers }\end{array}$ & 100 & 49.55 & 35.79 & 0.047 & -1.430 & 0.811 & \\
\hline $\begin{array}{l}\text { Willingness of Comm., with an acquain- } \\
\text { tance }\end{array}$ & 100 & 81.80 & 28.01 & -1.645 & 1.630 & 0.787 & \multirow[t]{4}{*}{0.890} \\
\hline $\begin{array}{l}\text { Willingness of Comm., in a large meeting } \\
\text { of acquaintances }\end{array}$ & 100 & 76.28 & 29.90 & -1.215 & 0.384 & 0.209 & \\
\hline $\begin{array}{l}\text { Willingness of Comm., in a small group of } \\
\text { acquaintances }\end{array}$ & 100 & 83.59 & 25.13 & -1.805 & 2.638 & 0.727 & \\
\hline $\begin{array}{l}\text { Willingness of Comm., to a group of ac- } \\
\text { quaintances }\end{array}$ & 100 & 75.76 & 29.46 & -1.197 & 0.398 & 0.405 & \\
\hline $\begin{array}{l}\text { Willingness of Comm., in a large meeting } \\
\text { of friends }\end{array}$ & 100 & 87.93 & 22.22 & -2.268 & 4.911 & 0.787 & \multirow[t]{4}{*}{0.805} \\
\hline Willingness of Comm., with a friend & 100 & 95.81 & 13.36 & -4.635 & 24.555 & 0.209 & \\
\hline $\begin{array}{l}\text { Willingness of Comm., with a group of } \\
\text { friends }\end{array}$ & 100 & 87.38 & 22.79 & -2.132 & 4.174 & 0.727 & \\
\hline $\begin{array}{l}\text { Willingness of Comm., in a small group of } \\
\text { friends }\end{array}$ & 100 & 94.30 & 15.04 & -3.669 & 15.351 & 0.405 & \\
\hline Motivation on Exercising, Next Week & 100 & 74.52 & 29.18 & -0.992 & 0.022 & 0.893 & \multirow[t]{4}{*}{0.984} \\
\hline Motivation on Exercising, Second Week & 100 & 72.83 & 29.89 & -0.879 & -0.292 & 0.960 & \\
\hline Motivation on Exercising, Three Weeks & 100 & 71.61 & 31.09 & -0.826 & -0.504 & 0.974 & \\
\hline Motivation on Exercising, Four Weeks & 100 & 70.52 & 32.19 & -0.787 & -0.640 & 0.973 & \\
\hline Motivation on Exercising, Five Weeks & 100 & 69.26 & 32.47 & -0.726 & -0.723 & 0.980 & \multirow[t]{4}{*}{0.993} \\
\hline Motivation on Exercising, Six Weeks & 100 & 68.04 & 33.30 & -0.659 & -0.889 & 0.973 & \\
\hline Motivation on Exercising, Seven Weeks & 100 & 66.87 & 34.06 & -0.617 & -0.988 & 0.960 & \\
\hline Motivation on Exercising, Eight Weeks & 100 & 66.38 & 34.57 & -0.587 & -1.050 & 0.946 & \\
\hline
\end{tabular}


Table 2. Path weights

\begin{tabular}{l|c|c|c}
\hline \multicolumn{1}{c|}{ Parameter Estimate } & $\begin{array}{c}\text { Non- } \\
\text { standardized }\end{array}$ & Standardized & $p$-value \\
\hline History of Playing $\rightarrow$ Engaging in Exercise & 0.632 & 0.115 & .031 \\
\hline $\begin{array}{l}\text { Engaging in Exercise } \rightarrow \text { Willingness of Communication } \\
\text { with Strangers }\end{array}$ & 0.106 & 0.305 & $.000^{* * *}$ \\
\hline $\begin{array}{l}\text { Engaging in Exercise } \rightarrow \text { Willingness of Communication } \\
\text { with Acquaintance }\end{array}$ & 0.037 & 0.147 & $.010^{* *}$ \\
\hline $\begin{array}{l}\text { Engaging in Exercise } \rightarrow \text { Willingness of Communication } \\
\text { with Friends }\end{array}$ & 0.018 & 0.100 & $0.093^{\text {ns }}$ \\
\hline $\begin{array}{l}\text { Engaging in Exercise } \rightarrow \text { Likelihood of Consistently En- } \\
\text { gaging in Exercising in the Short Term }\end{array}$ & 0.034 & 0.115 & $.036^{*}$ \\
\hline $\begin{array}{l}\text { Engaging in Exercise } \rightarrow \text { Likelihood of Consistently En- } \\
\text { gaging in Exercising in the Long Term }\end{array}$ & 0.050 & 0.140 & $.010^{*}$ \\
\hline
\end{tabular}

- Note: $\mathrm{CFI}=.912 ; \mathrm{SRMR}=.038 ; \mathrm{RMSEA}=.096$

- n.s.: not significant; *: $\mathrm{p}<.05 ; * *: \mathrm{p}<.01 ; * * *: \mathrm{p}<.001$ 